\title{
Granulometria da fração areia de alguns perfis de solos de Aripuanà - MT
}

\author{
R. R. Aloisi $\left({ }^{*}\right)$ \\ D. Perecin (*) \\ N. R. Boni $(*)$
}

Resumo

0 abjetivo do presente trabalho é fornecer informaçōes que visam ao auxilio na caracterização dos sedimentos que ocorram na área do Aripuanã-MT. Os resultados indicam que a fração areia dos horizontes apresenta predominância das subfrações finas, seleção pobre e curvas muito assimétricas o que indica que o diâmetro médio não é representativo da fração areia.

\section{INTRODUÇÃo}

Vișa o presente trabalho, a obtenção de dados e informações sobre $\alpha$ aspecto sedimentológico de perfis que ocorrem na área de Aripuanã (MT), de modo a auxiliar a caracterização de sedimentos que deram origem aos solos da região.

\section{CARACterização GERAL DA ÁREA}

O Núcleo Pioneiro de Humboldt, local de desenvolvimento de pesquisas constantes do Projeto Aripuanã, localiza-se no Município de Aripuanã-MT, e situa-se em região coberta por vegetação de tipo floresta aberta, desenvolvida em clima Tropical Úmido, do tipo climático Am (Köppen) .

A geologia da área é representada por dobramentos Pré-Cambrianos, encimados por cobertura arenítica (Brasil Min. \& Agri. Projeto RADAM), o que impõe a esta região relevo plano a ondulado.

Seus solos são representados, na maioria, pelo Latossol Vermelho-Amarelo que se apresentam com alta fertilidade aparente, relevo normal, profundidade efetiva boa, drenagem interna comprometida e erosão bastante pronunciada.

\section{MATERIAL E MÉtodos}

\section{MATERIAL}

\section{Solos}

Utilizou-se para o presente trabalho, perfis de solos da área de implantação do Projeto Aripuanã, classificados como Latossol Vermelho Amarelo Distrófico textura média e Latossol Vermelho Amarelo Distrófico textura argila.

\section{MÉTODOS}

\section{Coleta e preparo das amostras}

Através de trincheiras abertas na área de acorrência do solo em questão, coletou-se amostras de cada horizonte, tomando-se aproximadamente $1 \mathrm{~kg}$ de solo com 4 repetições, as quais, acondicionadas em sacos plásticos, foram conduzidas ao laboratório para posteriores tratamentos, onde procedeu-se a sua secagem, destorroamento, peneiramento e armazenamento.

\section{Obtenção da fração areia}

Destas amostras, tomou-se $150 \mathrm{~g}$ submetendo-as a um processo preliminar de dispersão com $\mathrm{NaOH} \mathrm{N}$. Em seguida procedeu-se a lavagem de amostras em peneiras de malha 230 Mesh. O material retido na peneira de 230 Mesh foi passado em peneira de 10 Mesh para eliminação dos calhaus, que continham muitas concreções cuja origem não foi pesquisada.

Submeteu-se a seguir os sedimentos retidos a um tratamento com $\mathrm{HCl} 2: 1$ a quente, por um período de 2 horas, a fim de se eliminar os agentes cimentantes do solo.

A areia assim obtida, ou seja, a fração areia total, foi novamente lavada para eliminação de resíduos de ácido, e seca em estufa.

(•) - Prof. dos Departamentos de Solos e Adubos e Ciências Exatas da Faculdade de Ciências Agrárias e Veterinárias de Jaboticabal - UNESP. 


\section{Obtenção das subfraçōes de areia total}

A fração areia total foi colocada em um conjunto de peneiras com diâmetro $18,35,45$, $60,80,120,140,170$ e 230 (Mesh), levado para o agitador por 10 minutos.

O materia! retido em cada peneira foi pesado para posterior utilização na construção das curvas acumuladas.

\section{Tratamentos estatísticos}

A análise estatística visa obter informações que tornam possivel descrever os sedimentos em termos de suas propriedades, tais como: diâmetro médio, grau de seleção, grau de assimetria e curtose, desenvolvidos estatisticamente por Sahu (1964) utilizando as estatísticas definidas por Folk \& Ward (1957).

$$
\mathrm{M}_{\mathrm{z}}=\frac{\text { Diâmetro Médio }\left(\mathrm{M}_{\mathrm{z}}\right)}{\$ 16+\phi 50+\phi 84}
$$

Geologicamente, esse parâmetro reflete a média geral de tamanho dos sedimentos, sendo afetada pela fonte de suprimento do material, pelo processo da deposição e·pela velocidade da corrente.

Observa-se pela fórmula, tratar-se de uma média aritmética dos valores correspondentes ao diâmetro médio das frações grossas, média e fina dos sedimentos.

$$
\begin{aligned}
& \frac{\text { Desvio Padrão (ór) }}{\text { ó }}=\frac{\phi 84+\phi 16}{4}+\frac{\phi 95+\phi 5}{6,6}
\end{aligned}
$$

Essa medida representa a seleção da fração areia do sedimento.

$$
\begin{aligned}
& \text { Assimetria }\left(\mathrm{SK}_{\mathrm{I}}\right) \\
& \mathrm{SK}_{\mathrm{I}_{2}}=\frac{\phi 84+\phi 16-2 . \phi 50}{(\phi 84-\phi 16)}+\frac{\phi 95+\phi 5-2 . \phi 50}{2(\phi 95-\phi 5)}
\end{aligned}
$$

Esta fórmula mede o grau de assimetria das freqüências da distribuição de pesos, e define a posição da média em relação à mediana.

$$
\begin{aligned}
& \text { Curtose }\left(\mathrm{Kg}_{\mathrm{g}}\right) \\
& \qquad \mathrm{Kg}=\frac{\phi 95-\phi 5}{2,44(\phi 75-\phi 25)}
\end{aligned}
$$

Esta medida indica a razão de espalhamento médio nas caudas das curvas. Retrata o grau de agudez dos picos das curvas de distribuição de freqüência.

\section{REsultados E Discussão}

Utilizando-se da metodologia adequada, submeteu-se a fração areia total ao. peneiramento obtendo-se seu parcelamento em subfrações. cujos valores médios obtidos com 4 repetições acham-se dispostos no Quadro 1.

As curvas acumulativas por questão de es. paço são suprimidas apresentando-se apenas os valores dos percentis no Quadro 2 e dos coeficientes estatísticos no Quadro 3.

\section{DIÂMETRO MÉDIO}

Na estimativa da média geral do tamanho dos grânulos da areia dada pelos diâmetros médios $\left(\mathrm{M}_{\mathrm{Z}}\right)$ apresentados no Quadro 3, observa-se que a variação foi de 2,57 a 3,07 no perfil 1, de 2,48 a 2,77 no perfil 2 e de 2,22 a 2,78 no perfil 3 . Há portanto pouca uniformidade tanto entre horizontes como entre perfis e o diâmetro médio caracteriza a fraçăo areia como constituida de suas subfrações finas.

\section{DESVIO PADRÃO}

$\mathrm{Na}$ avaliação da seleção dos materiais es. tudados pode-se notar, através do Quadro 3, que o comportamento apresentado pelos perfis são diferentes. Assim, segundo Suguio (1973), o perfil pode-se ser classificado como bem selecionado embora o horizonte $B_{22}$ apresente valor de desvio padräo (ól) superior a 1. 
OUADRO 1 - Valores dos pesos médios $(\mathrm{g})$, obtidos com 4 repetições, nos três perfis

\begin{tabular}{|c|c|c|c|c|c|c|c|c|c|c|c|c|c|c|c|c|c|c|}
\hline \multirow{2}{*}{\multicolumn{2}{|c|}{$\begin{array}{l}\text { Perfis } \\
\text { Horizontes }\end{array}$}} & \multicolumn{7}{|c|}{ P1 } & \multicolumn{6}{|c|}{$\mathrm{P} 2$} & \multicolumn{4}{|c|}{ P3 } \\
\hline & & Ap & B1 & B21 & B22 & B3 & C & Trado & Ap & B1 & B2 & C1 & C2 & Trado & Ap & B2 & $\mathrm{C} 1$ & C2 \\
\hline$\phi$ & Mesh & & & & & & & & & & & & & & & & & \\
\hline 0 & 18 & 1,20 & 1,0 & 1,6 & 1.5 & 1,5 & 1,4 & 1,7 & 1,4 & 2,1 & 2,4 & 1.5 & 1,4 & 2,9 & 0.8 & 1,6 & 3.1 & 3,0 \\
\hline 1 & 35 & 1.70 & 1,0 & 1,7 & 1,5 & 1.4 & 1.3 & 1,4 & 1,8 & 1.7 & 2,5 & 1,3 & 1,4 & 4,1 & 1,4 & 1,8 & 2,6 & 2.7 \\
\hline 1,5 & 45 & 0.83 & 0,7 & 0,6 & 1.0 & 0.5 & 0.5 & 0,6 & 0,9 & 0.7 & 0.6 & 1.9 & 0.4 & 1,4 & 0,8 & 0,6 & 0.8 & 0,8 \\
\hline 2,0 & 60 & 1,43 & 3.6 & 1.1 & 0,8 & 0,7 & 0.7 & 0.7 & 1,0 & 0.8 & 0,6 & 0.3 & 0,3 & 1,0 & 0.8 & 0,5 & 0.6 & 0,6 \\
\hline 2,5 & 80 & 10.1 & 6.6 & 5,3 & 4,6 & 4.5 & 4,5 & 5,3 & 4,6 & 3,7 & 0,6 & 1,4 & 1.2 & 2,2 & 4,3 & 2.1 & 2.0 & 1,8 \\
\hline 3,0 & 120 & 16,5 & 12,0 & 16,3 & 9,4 & 9.2 & 10.0 & 12,9 & 6,5 & 6.0 & 5.7 & 3,1 & 2,6 & 2,5 & 7.4 & 4,7 & 4.4 & 3.8 \\
\hline 3,25 & 140 & 12,4 & 7,9 & 6.6 & 8.7 & 8.1 & 7,9 & 12,3 & 5,3 & 4,1 & 4,4 & 2.5 & 2,0 & 3.5 & 5.0 & 3.7 & 3.9 & 4,7 \\
\hline 3.5 & 170 & 9.0 & $8,0$. & 10,5 & 6,9 & 6,9 & 6.4 & 8,4 & 4,4 & 4,2 & 8.8 & 3,2 & 2.8 & 3.7 & 2,7 & 3.8 & 4.0 & 4.0 \\
\hline 4.0 & 230 & 8.7 & 8.6 & 8.5 & 7.2 & 7.0 & 7.2 & 7.9 & 4.6 & 5,4 & 4,4 & 4,2 & 4.6 & 4,0 & 4,4 & 3.8 & 4.6 & 3,4 \\
\hline
\end{tabular}

Nos perfis 2 e 3, observa-se que, com exceçāo dos horizontes superficiais $A_{p}$ (valores de ÓI inferior a 1), todos os demais são classıficados como pobremente selecionados.

No geral, portanto, há predominância do mal selecionamento.

\section{ASSIMETRIA}

O Ouadro 3, também apresentando os valores de assimetria $\left(\mathrm{SK}_{\mathrm{I}}\right)$, indica que a variação se enquadra como assimetria muito negativa, segundo classificação de Suguio (1973).

Isso mostra que há uma acentuada predominância das subfrações areias de menor diâ. metro, podendo-se notar, nos Quadros 2 e 3. $\phi 50$ (mediana) é sempre menor que $\mathrm{M}$.

\section{CURTOSE}

Os valores de curtose (Quadro 3) apresentam variação entre os horizontes e entre os perfis.

Os valores da curtose no perfil 1, baseado em Suguio (1973), indicam as seguintes curvas: muito leptocúrticas para o horizonte $A p$; extremamente leptocúrticas para o horizonte $\mathrm{B}_{2}$ e leptocúrticas para os demais horizontes.

No perfil. 2, com exceção do horizonte $B_{22}$ cujos valores da curtose indicam curva extremamente leptocúrtica, os demais horizontes apresentam curvas leptocúrticas.
Finalmente, a análise dos valores de curtose no perfil 3 , apresenta as seguintes curvas: extremamente leptocúrtica para o horizonte Ap e $B_{2}$, mesocúrtica para o horizonte $C_{1}$ e platicúrtica para o horizonte $C_{2}$ (Suguio, 1973).

No geral, portanto, há acentuada predominância de curvas leptocúrticas.

QUADRO 2 - Valores do $\Phi$ utilizados para o cálculo dos parâmetros estatisticos

\begin{tabular}{|c|c|c|c|c|c|c|c|c|}
\hline & & $\phi^{5}$ & $\phi^{16}$ & $\Phi^{25}$ & $\phi^{50}$ & $\phi^{75}$ & $\Phi^{84}$ & $\phi^{95}$ \\
\hline \multirow{7}{*}{ 湈 } & $A_{p}$ & 0,86 & 2,24 & 2,50 & 2,99 & 3,22 & 3,42 & 3,79 \\
\hline & $\mathrm{B}_{1}$ & 0.96 & 2,15 & 2,48 & 3.41 & $3,46^{\prime}$ & 3,64 & 3,85 \\
\hline & $B_{21}$ & 0,66 & 2,30 & 2,56 & 3,00 & 3,35 & 3,51 & 3,52 \\
\hline & $B_{22}$ & 0.71 & 1,16 & 2,55 & 3,04 & 3,38 & 3,52 & 3,85 \\
\hline & $\mathrm{B}_{3}$ & 0,54 & 2,23 & 2,52 & 3,06 & 3,72 & 3,56 & 3,82 \\
\hline & C & 0,55 & 2,12 & 2,59 & 3,04 & 3.47 & 3,45 & 3.78 \\
\hline & Trado & 1,20 & 2.49 & 2.67 & 3,08 & 3.36 & 3,49 & 3,71 \\
\hline \multirow{7}{*}{ 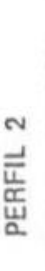 } & & & & & & & & \\
\hline & $A_{p}$ & 0,12 & 1,48 & 2,26 & 2,96 & 3,36 & 3,43 & 3,72 \\
\hline & $B_{1}$ & $-1,72$ & 1,48 & 2,26 & 2,96 & 3,36 & 3,43 & 3,72 \\
\hline & $\mathrm{B}_{2}$ & $-1,92$ & 1,20 & 2,39 & 3.12 & 3,58 & 3,60 & 3,87 \\
\hline & $\mathrm{C}_{1}$ & $-1,65$ & 1.09 & 2,63 & 3,04 & 3,33 & 3,64 & 3,86 \\
\hline & $\mathrm{C}_{2}$ & -1.68 & 0.94 & 2,27 & 3,12 & 3,55 & 3,72 & 3,90 \\
\hline & Trado & $-1,45$ & 1,27 & 1,83 & 2,70 & 3.32 & 3,84 & 3,84 \\
\hline \multirow{4}{*}{$\begin{array}{l}m \\
\text { 蔗 } \\
\text { 吉 }\end{array}$} & $A p$ & 0.44 & 2,06 & 2,38 & 2,88 & 3.27 & 3,40 & 3,85 \\
\hline & $\mathrm{B}_{2}$ & -1.78 & 1,28 & 2,45 & 2,98 & 3,37 & 3.54 & 3.84 \\
\hline & $c_{1}$ & $-1,40$ & 0,37 & 1,60 & 2,97 & 3,34 & 3,46 & 3,71 \\
\hline & $\mathrm{C}_{2}$ & $-1,52$ & 0,32 & 1,32 & 2,94 & 3,35 & 3,40 & 3,81 \\
\hline
\end{tabular}


QUADRO 3 - Valores do Diâmetro Médio, Assimetria, Curtos e Desvio Padrão

\begin{tabular}{|c|c|c|c|c|c|}
\hline \multicolumn{2}{|c|}{ Horizonte } & \multirow{2}{*}{$\begin{array}{l}\mathbf{K g} \\
2,88\end{array}$} & \multirow{2}{*}{$\begin{array}{l}M_{\mathbf{z}} \\
1,67\end{array}$} & \multirow{2}{*}{$\begin{array}{r}\text { ól } \\
0,74\end{array}$} & \multirow{2}{*}{$\begin{array}{r}\mathbf{S K}_{\mathbf{I}} \\
-0,36\end{array}$} \\
\hline \multirow{7}{*}{$\frac{-}{\frac{1}{4}}$} & $A_{p}$ & & & & \\
\hline & $B_{1}$ & 3,07 & 1,21 & 0,81 & $-0,69$ \\
\hline & $\mathrm{B}_{21}$ & 2,94 & 1,48 & 0,74 & $-0,40$ \\
\hline & $\mathrm{B}_{22}$ & 2,57 & 1,55 & 1,06 & -0.54 \\
\hline & $\mathrm{B}_{3}$ & 2,95 & 1,12 & 0,83 & $-0,39$ \\
\hline & C & 2,87 & 1,50 & 0,83 & $-0,46$ \\
\hline & Trado & 3,02 & 1,49 & 0,63 & $-0,34$ \\
\hline \multirow{6}{*}{$\begin{array}{l}\text { N } \\
\frac{\vec{u}}{\frac{\pi}{\sigma}} \\
\frac{\tilde{u}}{\alpha}\end{array}$} & $A_{p}$ & 2,77 & 1,40 & 0.97 & $-0,39$ \\
\hline & $\mathrm{B}_{1}$ & 2,62 & 1,33 & 1,03 & -0.55 \\
\hline & $\mathrm{B}_{2}$ & 2,64 & 1,37 & 1,20 & $-0,61$ \\
\hline & $\mathrm{C}_{1}$ & 2,59 & 2,93 & 1,40 & $-0,40$ \\
\hline & $\mathrm{C}_{2}$ & 2,59 & 1,32 & 1,32 & $-0,59$ \\
\hline & Trado & 2,48 & 1,13 & 1.18 & $-0,37$ \\
\hline \multirow{4}{*}{ 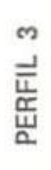 } & $A_{p}$ & 2,78 & 1,57 & 0.85 & -0.33 \\
\hline & $\mathrm{B}_{2}$ & 2,60 & 1,77 & 1,17 & $-0,54$ \\
\hline & $\mathrm{C}_{1}$ & 2,27 & 0,95 & 1,38 & $-0,66$ \\
\hline & $\mathrm{C}_{2}$ & 2,22 & 0,81 & 1,38 & $-0,63$ \\
\hline
\end{tabular}

\section{SUMMARY}

The objective of this work was give help in the characterization of the sediments that occur around Aripuanã - MT.

There were applied statistical parameters in the data of sand sub-fractions obtained in the 3 profiles that represent the area

\section{BIBLIOGRAFIA CTTADA}

BrasiL. Ministério da Agricultura. Projeto RADAM.

s.d. - Levantamento exploratório - Reconhecimento de solos da Área do Projeto Aripuanā. $109 \mathrm{p}$.

FOLK, R. L. \& WARD, W.

1957 - Brazos Riverbar: a study in the significance of grain size parameters. J. Sed. Petrol. $27: 3-27$.

SAHU, B. K.

1964 - Depositional mechanism from the size analysis of the clastic sediments. J. Sed. Petrol , 34: 73-83.

Suguio, $\mathrm{K}$.

1973 - Introdução à sedimentologia. São Paulo, Edgard Blucher/USP. $317 \mathrm{p}$.

(Aceito para publicaçāo em 22/12/77) 